\title{
Blok Zincir Teknolojisi ve Tedarik Zinciri Yönetimindeki Uygulamaları
}

\author{
DOI: 10.26466/opus.563240 \\ * \\ İsmail Bakan* - Zümrüt Hatice Șekkeli**
}

* Prof. Dr, Kahramanmaraş Sütçü İmam Üniversitesi, İ̈BF, Onikişubat / Kahramanmaraş / Türkiye
E-Posta: ibakan63@hotmail.com
ORCID: $\quad$ 0000-0001-8644-8778
** Dr. Öğr. Üyesi, Kahramanmaraş Sütçü İmam Üni., Türkoğlu MYO, Türkoğlu

/Kahramanmaraş/Türkiye

E-Posta: zhkiper@gmail.com

ORCID: $\quad \underline{0000-0001-5090-4372}$

Öz

Net bir tanımı bulunmamakla birlikte blok zincir kavramını; "süreçte yapılan her bir faaliyete ilişkin verilerin, şifreli bir biçimde, belirli aralıklarla ve kronolojik olarak kaydedildiği ve her bir bloğun bir önceki bloğun bilgilerini de içerdiğgi bilgi bloklarmmn art arda gelerek oluşturduğu zincir" olarak tanımlamak mümkündür (Mattila, 2016,s.6-7; Tian, 2016). Elektronik para birimi Bitcoin sisteminin güvenliğini săglamak amacıyla ortaya konan blok zincir teknolojisi, son zamanlarda finansal alanlarm dışında çeşitli alanlarda da yer bulmaya başlamıştır (Hackius \& Petersen, 2017,s.5). Bunlardan bir tanesi de yetersiz bilgiye sahip olan ve şeffaf olmayan tedarik zinciri yönetim süreçlerdir. Tedarik zincirinin neden olduğ u dengesizliği çözmesi, tedarikçilerden müşterilere kadar tüm zincirde şeffaflı̆̆ın, sürdürülebilir izlenebilirliğin ve güvenliğin artırılmasın sağlaması (Badzar, 2016) nedeniyle blok zinciri teknolojisinin; tedarik zinciri yönetimine de oldukça pozitif bir katkı sağlayacağı düşünülmektedir (Hackius \& Petersen, 2017). Bu çalışmanın temel amacı blok zincir teknolojisi ve bu teknolojinin tedarik zinciri yönetim alanındaki uygulamaları hakkında bilgi sunmak; bu yolla tedarik zinciri süreçlerine yönelik araştırmalara katkı sağlamaktır. Bu amaçla uluslararası literatürde bu konuda kitaplar, dergiler, tezler, internet kaynaklarn gibi kaynaklardan literatür incelemesi yapılarak, blok zincir teknolojilerinin tedarik zinciri yönetim uygulamalarına sunacă̆ faydalar teorik açıdan açıklanmıştır.

Anahtar Kelimeler: Blok Zinciri Teknolojisi, Tedarik Zinciri Yönetimi, Uygulamaları 


\title{
Blockchain Technology and Its Applications in Supply Chain Managements
}

\begin{abstract}
Although there is any clear definition of the concept of block chain; it can be defined as "the as a chain of information blocks, which data for each activity in the process are stored in an encrypted format, periodically, chronologically and that each block contains the information of the previous block in succession" (Mattila, 2016,p.6; Tian, 2016) At the beginning, it is used in order to ensure the security of the electronic currency bitcoin system, the block chain technology, has been begun to use not only various financial areas but also different various areas nowadays (Hackius \& Petersen, 2017,p.5). One of these areas is the supply chains management because of its insufficient knowledge and nontransparent processes. To solve the imbalance caused by the supply chain, to ensure transparency, sustainable traceability and security increase in the entire chain from suppliers to customers (Badzar, 2016); blockchain technology is used thought supply chain management. The main purpose of this study is to provide information on blockchain technology and its applications to develop management processes at the logistics area. For this purpose, to understand the benefits of blockchain technologies on the supply chain management in theoretically; literature review from sources such as international literature, books, magazines, theses, Internet resources etc. was made.
\end{abstract}

Keywords: Blockchain Technology, Supply Chain Management, Applications 


\section{Giriş}

Günümüzde yaşanan teknolojik gelişmeler, bu değişime bağlı olarak iletişimin kolaylaşması ve yaygınlaşması, küreselleşmenin varlığı, dünyadaki siyasi ve ekonomik politikaların sürekli değişmesi, müşteri beklentilerinin sürekli olarak çeşitlenmesi gibi faktörler nedeniyle rekabet etmek gün geçtikçe zorlaşmıştır (Babacan, 2003,s.8). Bu süreçte bahsi geçen bütün bu değişim ve gelişimlere adapte olabilmek için işletmeler Tedarik Zinciri Yönetimine daha fazla ağırlık vermeye başlamışlardır

Tedarik zinciri, mal veya hizmetin, hammadde tedarikinden tüketiciye ulaşana kadar, tedarikçiler, üretim merkezleri, depolar, dağıtım merkezleri, perakendeciler vs. paydaşların koordine edilmesini sağlayan ve yapılan faaliyetlerin yürütülmesi ve denetimini kapsayan bir zincir olup (Lai ve Cheng, 2016), etkili bir şekilde yönetilmesi işletmelere maliyetlerin azaltılması ve müşteri memnuniyetinin artırılması konularında avantajlar sağlamaktadır (Ungan, 2011, s.308).

Doğru yöntemlerle ve düzgün bir şekilde yapılması şirketin büyümesi, kar oranının artması, maliyetin azalmasını sağlayan tedarik zinciri yönetimi, tüm şirketler için oldukça kritik bir öneme sahiptir. Bir tedarik zinciri yönetirken en sık karşılaşılan sorunlar; yetersiz ekipman ve ödenek nedeniyle erişilebilen bilginin yetersiz kalması yani izlenebilirliğin istenilen düzeyde olmamasıdır. Bunun sonucunda da gereken düzeltici müdahaleler yeterince yapılamamaktadır (Tian, 2016). Ayrıca hammaddelerin farklı yerlerden tedarik edilmesi, çok çeşitli üretim süreçlerinin bulunması, dağıtım kanallarında farklı ülkelerden çok çeşitli paydaşların yer alması, ürünlerin teslim sürecinde farklı coğrafyalardan geçmesi, her devletin gümrük uygulamalarının farklı olması, birçok ödeme şekillerinin bulunması, belgelerin kaybedilmesi ve kurumlara ya da süreçlere duyulan güvenin yetersiz olması nedeniyle tedarik zinciri süreçleri gittikçe daha da kompleks hale gelmiştir. Blok zincir teknolojisi, tedarik zincirindeki bu gibi birçok soruna çözüm vadetmektedir (Akben ve Çinar, 2018,s.1453).

Blok zinciri, her bir blokun, o an yapılan işlemleri ve bir önceki blokun adresini tutması sistemine dayalı olan blok zincir teknolojisi, işlemlerin değiştirilemez listesinin tutulduğu bir nevi kayıt defteridir (ledger) (Karaarslan ve Akbaş, 2017). Birçok bloğun sıralanması ile oluşan bu uygulama, 
geçmişten bugüne olan tüm ağ üzerinde gerçekleşmiş aktiviteleri, kronolojik bir biçimde özel bir şifreleme ve doğrulatma sistemiyle kayıt altına alabilmekte ve güvenli bir şekilde saklayabilmektedir. Bu nedenle blok zincir teknolojisi, tedarik zincirinin performansını artırmak adına, tedarik zinciri yönetimi konusunda çok etkin çözümler sunabilen ve inovatif özelliklere sahip bir teknolojidir (Tribis, El Bouchti, Bouayad, ve El Ghazi, 2018, s.1)

$\mathrm{Bu}$ çalışmada blok zincir teknolojisi ve bu teknolojinin tedarik zinciri yönetimi alanındaki uygulamaları hakkında bilgi sunarak tedarik zinciri yönetim süreçleri ile ilgili araştırmalara katkı sağlamak amaçlanmaktadır. Bu amaçla blok zinciri ile ilgili olarak ulusal ve uluslararası literatür taranmış; bu çalışmalardan tedarik zinciri yönetimine yönelik olanlar derlenerek sunulmuştur.

Çalışmanın ikinci bölümünün birinci kısmında blok zincir teknolojisinin tanımı, yapısı, işleyişi faydaları, türleri ve uygulama alanları kavramsal çerçevede açıklanmıştır. İkinci kısımda ise blok zincir teknolojisinin tedarik zinciri üzerindeki uygulamaları, tedarik zinciri yönetimine sağladı̆̆ı yararlar bu konuda yapılmış çalışmalara dair bilgiler bulunmaktadır. Sonucun yer aldığı üçüncü bölümde de bulguların özeti ve özet bir değerlendirme yer almaktadır.

\section{Kavramsal Çerçeve}

\section{Blok Zincir (Blockchain) Teknolojisi}

Günümüzde Internet üzerinden Facebook, Instagram, Twitter vs. sosyal medya uygulamaları, Yahoo, Hotmail, Gmail vs. e-mail programları, Whatsapp, Messenger vs. gibi haberleşme yazılımları, e-ticaret siteleri, elojistik, e-sağlık, e-devlet gibi farklı ihtiyaçlara yönelik uygulamalar aracılığıyla çok çeşitli alanlarda ve konularda veri transferi yapılmaktadır. Bunlar genellikle güvenlik düzeyi düşük olan transferlerdir. Daha değerli veya özel varlıkların transferi bu sistemler aracılığıyla değil dağıtık bir veri tabanı olan "Blok Zincir Teknolojisi” ile yapılmaktadır. Bu teknoloji, sunduğu imkanlar ve çeşitlendirilebilir uygulamaları ile yüksek verimlilik vadetmektedir (http://blokzincir.tubitak.gov.tr ). 


\section{Blok Zincirin Tanımı ve İşleyişi}

Blok zincir kavramının çok net bir tanımı bulunmamaktadır. İlk olarak bu kelime 2008 yılında Satoshi Nakamoto'nun Bitcoin kavramı ile birlikte gündeme gelmiş ve şifreleme yoluyla birbirine bağlanmış bilgi blokları olarak tanımlanmıştır (Jacobovitz, 2016, s.2)

Blok zincir teknolojisinin özü daha önce toplanarak muhafaza edilmiş güvenilir verilerin teknik bir şema haline getirilmesiyle oluşmaktadır. Bu teknik şema, sistemde bulunan çok sayıda düğümün şifrelenmesi yoluyla oluşan bloklardan meydana gelmektedir. Bu nedenle blokların zinciri olarak adlandırılmaktadır. Blok zincirinde çok sayıda bloklar yer almaktadır. Bu bloklar doğrusal ve kronolojik olarak bir zincir oluşturacak şekilde birbirlerine bağlanmaktadırlar. Bu bloklar bilgilerin geçerliliğini doğrulayan dijital parmak izlerine sahiptirler (Tian, 2016).

Her bir blok içerisinde blok sırası, blok başlık özeti, bağlı bulunulan ve bir öncesinde yer alan bloğa ait başlı̆̆ın özeti, zorluk değeri, bloğun oluştuğu zamana dair zaman pulu, rastgele değeri ve transfer işlemlerine ait değerler bulunmaktadır (Şekil 1). Yapılan işlemlerin tamamı ağda bulunan bütün paydaşlar tarafından takip edilebilmektedir.

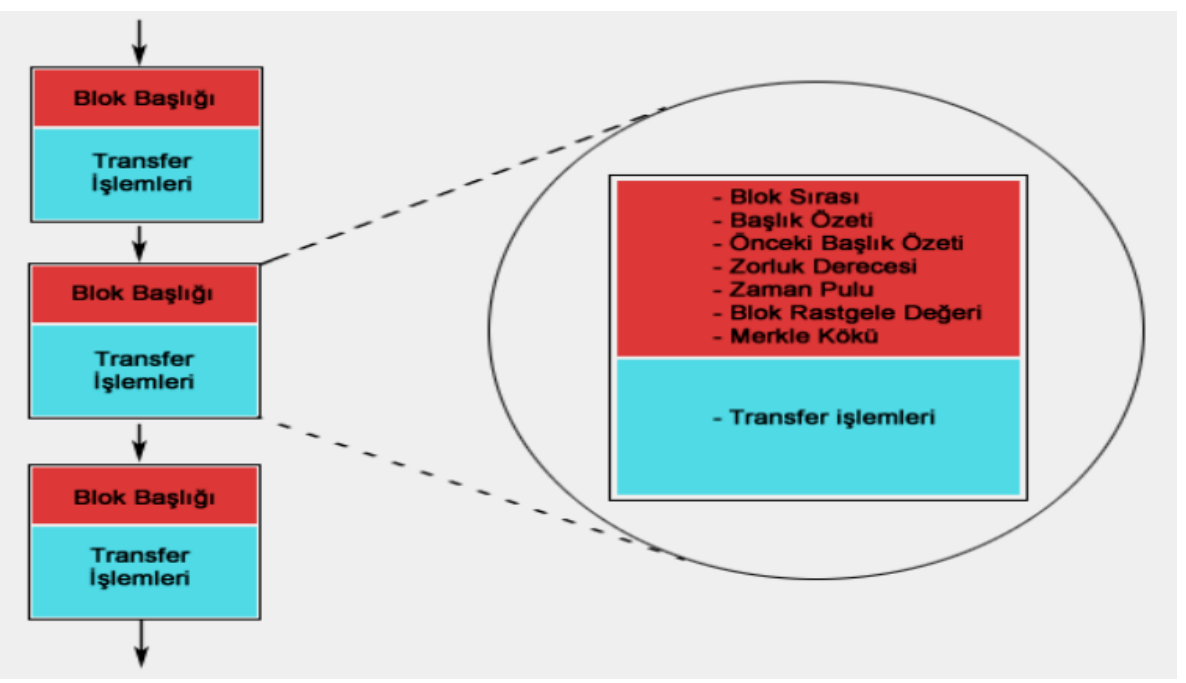

Şekil 1. Blok zincir yapısı (Kırbaş, 2018a,s.78) 
İşlemlerin geçerliliği onaylandıktan sonra işlemler bir araya getirilirler ve böylece bloklar oluşturulur. İşlem gören blok bir önceki geçerliliği onaylanmış blokla ilişkilendirildikten sonra ağdaki tüm paydaşlar bu yeni bloğu yerel veri tabanlarına ekleyerek senkronize olurlar (Kırbaş, 2018a, s.79)

Blok zinciri teknolojisinde transferlerde gönderici ve alıcının adresi bilinmekle beraber kimliklerinin saptanması imkânsızdır. Çünkü bu zincir sisteminde gönderici ve alıcı haricindekiler hesapları denetleyememektedirler. Tüm hesaplar dijital güvenlik sistemleriyle korunan dijital cüzdanlarda saklanmaktadır (F. Yıldırım, 2015, s.86). Cüzdanlar genellikle sıcak ve soğuk olmak üzere iki şekildedir; soğuk cüzdan ilgili bilgilerin çalınma ve saldırı riskini azaltmak için çevrimiçi olmayan bir cüzdan adresinde tutulmasıdır. Sıcak cüzdan ise çevrimiçi olarak erişilebilen cüzdanlardır. Bu cüzdanların güvenliğinden çevrimiçi cüzdan hizmeti veren firmalar sorumludur (Kirbaş, 2018a, s.80).

Blok zinciri teknolojisi üç temel unsura dayanmaktadır (Şekil 1). Bunlar özerklik, doğrulanabilirlik ve değişmezliktir. Özerklik ile, herhangi bir otoriteye bağlı kalmadan işleyen, güven temelli bir alt yapıya sahip olan ve üyelik sistemiyle yürüyen bir ağ yapısına sahip olması kastedilmektedir. Herhangi bir üyenin gerçekleştirdiği bir muhasebe işlemi, blok zincirde bulunan ve Peer-2-Peer olarak adlandırılan çok sayıda bilgisayar arasında veri kopyası oluşturmak için kullanılan ağ program protokolü üzerinden (https://www.elektrikport.com/) paylaşılmaktadır. Bunun sonucunda da tüm ağda bulunan üyeler bu işleminin kopyasını kendi kayıtlarında saklayabilmektedirler.

Doğrulanabilirlik, tüm üyelerin özel şifrelere sahip olmalarını ve ağ üzerinde işlem yapabilmek için bu şifreleri kullanmalarını ifade etmektedir. Bu nedenle sadece şifresi olanlar ağa giriş yapabilmektedirler. Ancak üyeler isterlerse anonim kalabilmektedirler, çünkü şifreler gerçek dünyadaki kimliklerle ilişkilendirilmemiştir.

Değişmezlik unsuru ise, yazılımın uzlaşma tabanlı algoritmasından kaynaklanmaktadır. Yapılan tüm işlemler birlikte yeni bir blok oluşturacak şekilde gruplandırılmaktadır. Ağda bulunan üyeler ilgili bloktaki işlemi doğrulayabilmektedirler. Eğer bir bloğun geçerliliği üzerinde uzlaşma sağlanmamışsa o blok reddedilmektedir. Aynı şekilde eğer bir blo- 
ğun geçerliliği üzerinde uzlaşma sağlanmışsa o blok zincire eklenmektedir. Şifreli içerik her bir blok için özel oluşturulmuştur ve sadece kendi içeriğini değil önceki bloğun içeriğini de kapsamaktadır (Hackius ve Petersen, 2017, s.6-7).

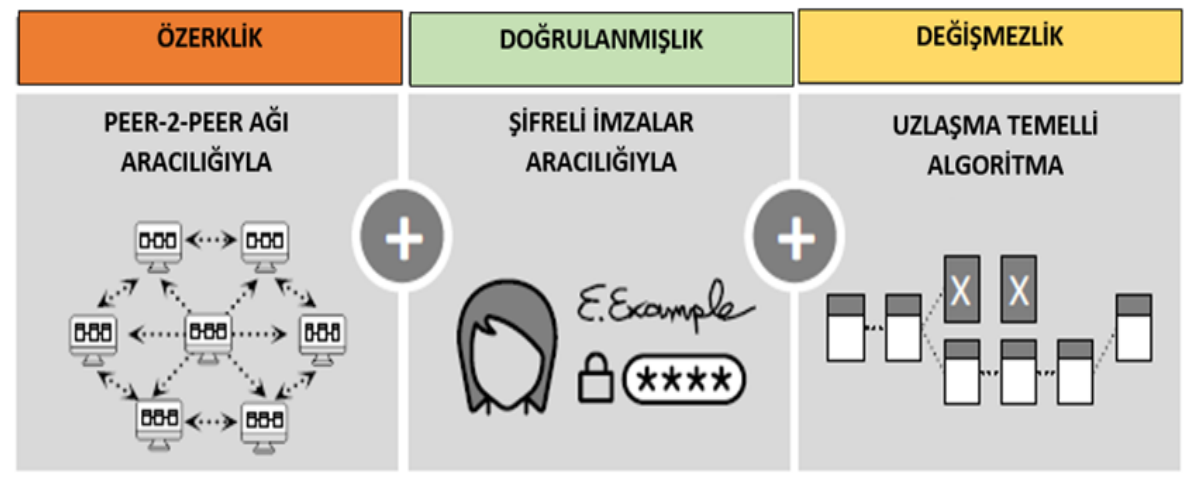

Şekil 2 Blok Zincir Unsurları (Ḧackius ve Petersen, 2017)

\section{Blok Zincir Türleri}

Blok zincirler erişim durumuna göre izin gerektirmeyen (İslamoğlu \& Alnıaçık), izin gerektiren (Kapalı) ve özel blok zincirleri olmak üzere üç çeşittir (Tablo 1).

Tablo 1. Blok zincir türleri (Wïst \& Gervais, 2017)

\begin{tabular}{llll} 
& $\begin{array}{l}\text { İzin Gerektirmeyen } \\
\text { (İslamoğlu \& } \\
\text { Alnıaç1k, 2014) } \\
\text { Blok Zincirleri }\end{array}$ & $\begin{array}{l}\text { İzin Gerektiren } \\
\text { (Kapalı) } \\
\text { Blok Zincirleri }\end{array}$ & $\begin{array}{l}\text { Özel Blok } \\
\text { Zincirleri }\end{array}$ \\
\hline İşlem hacmi & Düşük & Yüksek & Çok Yüksek \\
Bekleme süresi & Yavaş & Orta & Hizlı \\
Okuyucu sayısı & Yüksek & Yüksek & Yüksek \\
Yazar sayısı & Yüksek & Düsük & Yüksek \\
Güvenlik düzeyi & Düşük & Yüksek & Yüksek \\
Merkezi yönetim & Hayır & Evet & Evet \\
\hline
\end{tabular}

- İzin gerektirmeyen (İslamoğlu \& Alnıaçık) blok zincirler, açık ve merkezidirler. Herhangi biri bu ağlara kolaylıkla katılabilmektedir. İşlem 
hacmi daha düşük, bekleme süresi ise yavaştır. İzin gerekmediği için kullanıcı sayısı yüksek ancak güvenlik düzeyi düşüktür. Bitcoin, Ripple ve Ethereum sistemleri bu tip zincirlere örnektir. Bitcoin ve Ripple, dijital para birimleridir. Ethereum ise akıllı sözleşmeler yapılmasına imkân veren bir ödeme yöntemidir (https://sirazduvari.com/)

- İzin gerektiren (Kapalı) blok zincirler, sadece davet edilen katılımc1ların yer alabildiği zincirlerdir. Güvenlik ve gizliğin sağlanması için üyeler birbirlerine paralel olarak bağlı zincirlerde yer almaktadırlar. İşlem hacmi daha yüksek, bekleme süresi ise ortadır. İzin gerektiği için kullanıcı sayısı düşük ancak güvenlik düzeyi yüksektir. En yaygın bilinen kapalı blok zincirleri Hyperledger Fabric, Corda kanallarıdır (Wüst ve Gervais, 2017). IBM tarafından yönetilmekte olan Hyperledger Fabric, yüksek ölçekli blok zincir uygulamalar geliştirmeyi sağlayan temel bir projedir. İşletmeler için tasarlanmış açık kaynak kodlu bir blok zincir projesi olan Corda ise yoğun gizlilik ortamında daha çok finansal işlem yapabilen blok zincir ağları oluşturmayı sağlamaktadır (https://blockchaindanismanlik.com/).

- Özel blok zincirlerinde ise blok zincirine yazma (yeni bir işlem ekleme) yetkisi sadece özel bir gruba/organizasyona aittir. Verileri okuma hakkı ise herkese açık olabileceği gibi çeşitli şekillerde kısıtlanabilir.

\section{Blok Zincirinin Faydaları}

Blok zincir teknolojisinin birçok faydası bulunmaktadır. Bunlar (Durğay ve Karaarslan, 2018):

- Kayıtların değiştirilememesi verilerin çoklu düğümlerle doğrulanması ve tüm tarafların uzlaşması sayesinde güvenlik oldukça yüksektir.

- Ağda yer alan tarafların tamamının bilgiye erişimi kolay ve hızlıdır.

- Bilgiler merkezi olmayan, dağınık birden fazla defterin içinde saklandığı için kötü niyetli işlemlerin fark edilmeden yapılması mümkün değildir.

- Kullanıcı, şifreleme anahtarları aracılığıyla anonim olabilmektedir.

- İşlemler ve kontroller otomatik olarak yapıldığından insan kaynaklı hatalar azalmaktadır. 
- Herhangi bir merkez veya kuruma gerek olmadığından bir işlemi gerçekleştirme veya doğrulama maliyeti azaltılabilir.

- Şeffaftır ve kullanıcılar zincir içinde gerçekleşen tüm işlemleri eş zamanlı görebilmektedir.

- Sistemde yer alan bilgiler her seferinde oy birliğgi ile kaydedildiğinden veri doğruluğu ve kalitesi yüksektir.

\section{Blok Zincir Uygulama Alanları}

Blok zincirin en popüler uygulaması Bitcoin kripto paradır. Blok zincir sayesinde Bitcoin ve ondan sonra çoğalan kripto paraların tamamı sorunsuz bir biçimde sürdürülebilmiştir. Günümüzde ise hem finansal hem de finansal olmayan dünyada geniş uygulama alanına sahiptir (Crosby, M.,2015, s.7) Bunlar:

Finansal Uygulamalar:Pek çok banka ve finansal kurumları, blok zinciri teknolojisini ilk önce uluslararası para transferi ve uluslararası ticaretin finansmanı uygulamalarında, ardından da ödeme işlemleri, para transferleri, alış/satış platformları, sigorta, takas yönetimi, yetkilendirme, doğrulama, dijital kimlik yönetimi, doküman yönetimi gibi başka finansal kullanım alanlarında değerlendirmişlerdir (Ünsal ve Kocaoğlu, 2018b, s.58).

Akıllı Mülkiyet:Akıllı teknoloji yoluyla, maddi varlıklar (arabalar, evler, beyaz eşyalar, ofis gibi) ve maddi olmayan varlıklar (patentler, mülk unvanları, marka, şirket hisseleri gibi) bütünleştirilerek kayıt altına alınabilmektedirler. Bu kayıt sayesinde, ilgili varlığa sahip olma izni verilen kişi ya da kuruşlara dair bilgiler sözleşme detayları ile birlikte defterde saklanabilmektedir. İzin verilen kişi ya da kuruşlar bu bilgilere akıllı anahtarlar aracılığıyla kolayca erişebilmektedirler. Mülklerin akıllı hale getirilmesi dolandırıcılık, arabuluculuk ve şaibeli faaliyetlerin yapılması riskini azaltmakta; güven ve verimliliği artırmaktadır (https://bitcoinlerim.com/).

Nesnelerin Interneti: Nesnelerin internet tabanlı bir iletişim ağı üzerinden yazılım programları, RFID etiketleri, sensörler, tetikleyiciler, akıllı telefonlar vs. vasıtasıyla insanlarla ve birbirleriyle etkileşim kurması, bu yolla 
kendini duruma göre yapılandırabilmesi, bir kimliğe ve akla sahip olabilmesi biçiminde tanımlanan Nesnelerin İnterneti, sensör temelli bilgi ile insan temelli bilginin entegre olmasıyla daha doğru ve değerli bilgi elde etmeyi amaçlamaktadır (Bakan ve Şekkeli, 2017, s.21). Bu etkileşim süreçlerinin güvenli bir ortamda ve güvenli bir biçimle gerçekleştirilebilmesi blok zincir uygulamaları sayesinde olmaktadır.

Akıllı Sözleşmeler:Çoğunlukla kullanım alanı akıllı varlıkların alımı, satımı, transferi, ödünç verilmesi vs. olan akıllı sözleşmeler, kaynak kodlardan meydana gelmektedir. Sözleşmedeki basamaklar bir bilgisayar programının denetiminden geçmekte ve sözleşmenin uygulanması da süreç tarafından otomatik olarak gerçekleşmektedir (https://startuphukuku.com/).

Blok zincirinin kullanılmaya başlaması ile zincirin doğrulama unsuru güvensiz paydaşlarla olan işlemlerin güvenli hale gelmesini sağlamıştır. Özellikle sözleşme taraflarının çok sayıda olduğu ve birbirlerine güvenlerinin tam olmadığı durumlarda bu uygulama çok uygundur (Würst ve Gervais, 2017).

Devlet İșlerinde:Genellikle devlet tarafından yapılan Oylama, Doküman Yönetimi, Dijital Kimlik, Sosyal Güvenlik Sistemi, Vergi Sistemi gibi kamusal uygulamalarda kullanılmaktadır. Son yıllarda Dubai, İsviçre, İngiltere, Estonya, Singapur, Kıbrıs gibi bazı ülkeler, kamusal alanda blok zinciri yatırımları yapmaktadırlar (Ünsal ve Kocaoğlu, 2018, s.59).

Diğer uygulamalar : Blok zincirin diğer uygulama alanları şunlardır:

- Özel anahtarla şifrelenmiş ve sadece ilgili kişilerin erişimini mümkün kılan sağlık kayıtlarının tutulması, ilaç denetiminin yapılması, sonuçların test edilmesi ve sağlık malzemelerinin yönetimi gibi işlerde;

- Müzik endüstrisinde müzik haklarının merkezi ve kapsamlı bir veri tabanında tutularak sanatçıların şahsına ait telif hakları ve gerçek zamanlı dağıtımlarının şeffaf bir biçimde yapılması;

- Enerji sektöründe güneş panellerinin kendi kendinin güç miktarını değerlendirebilmesi, tüketiciye ulaşan enerji miktarının izlenebilmesi ve enerji satışı ve alımının yapılabilmesi; 
- Tarımsal uygulamalarda yetiştirme, ilaçlama ve ambalajlama süreçlerinin izlenmesinde ve onaylanmasinda;

- Tedarik zincirinde ürünün lojistik serüveni boyunca menşeini, rotasını, üretici firmasını, uygulanan işlemleri, tedarik sürecinin her aşamasında ödenen ücreti, taşınırken veya depolanırken oluşan 1sı, basınç vs. düzeyinin izlenebilmesi (Hackius ve Petersen, 2017; Kırbaş, 2018a; Kushch ve Prieto Castrillo, 2017, s.82; Petersen, Hackius, ve Von See, 2018; Rodrigue, 2018); https://bitcoinlerim.com/) diğer blok zincir uygulamalarıdır.

\section{Tedarik Zinciri Yönetiminde Blok Zincir (Blockchain) Teknolojisi}

Tedarik zinciri; hammaddenin çıkış noktasından üretime, ürün haline geldikten sonra da son müşteriye iletilmesi süreci boyunca; taşıma, depolama, stok yönetimi, elleçleme, dağıtım vs. faaliyetleri kapsayan bütünleşik bir ağdır. Tedarik zincirinin önemli bir parçası olan lojistik yönetimi süreci ise düşük maliyet ve yüksek kâr kriterlerini sağlamayı öncelikli tutarak, hammadde, ara ürün ve nihai ürünlerin akışı ve stoklanması gibi faaliyetlerin tedarik zinciri içinde stratejik bir şekilde yönetilmesidir. Bu nedenle de tedarik zinciri yönetimi sürecinin etkinliği lojistik yönetimi sürecinin etkinliği ile doğru orantılıdır; (Bakan ve Şekkeli, 2017, s.5; Bilginer, Kayabaşı, ve Sezici, 2008). Tedarik zinciri yönetimi, bu zincir içinde yer alan ilk tedarikçiden son kullanıcıya kadar tüm kişi, kurum ve kuruluşların stratejik bir biçimde koordine edilmesi yoluyla tek bir işletmeymiş gibi yönetilmesi olarak tanımlanmaktadır (Barutçu, 2007, s.134).

\section{Tedarik Zinciri ve Lojistik Yönetiminde Blok Zincir Uygulamaları}

Tedarik zincirleri, birden fazla aktör ve paydaşın yer aldığı birçok fiziksel akışın ve bu akışı destekleyen bilgi paylaşımlarının olduğu bir yapıdır. Bu yapı içerisinde siparişin alınmasından başlayarak doğru ürünün, doğru miktarda, doğru şartlarda, doğru konumda ve zamanda iletilmesine kadar birçok faaliyet yapılmaktadır. Blok zincir ve tedarik zincirlerinin uygulama mantığı bu açıdan büyük benzerlikler taşımaktadır (Rodrigue, 2018) 


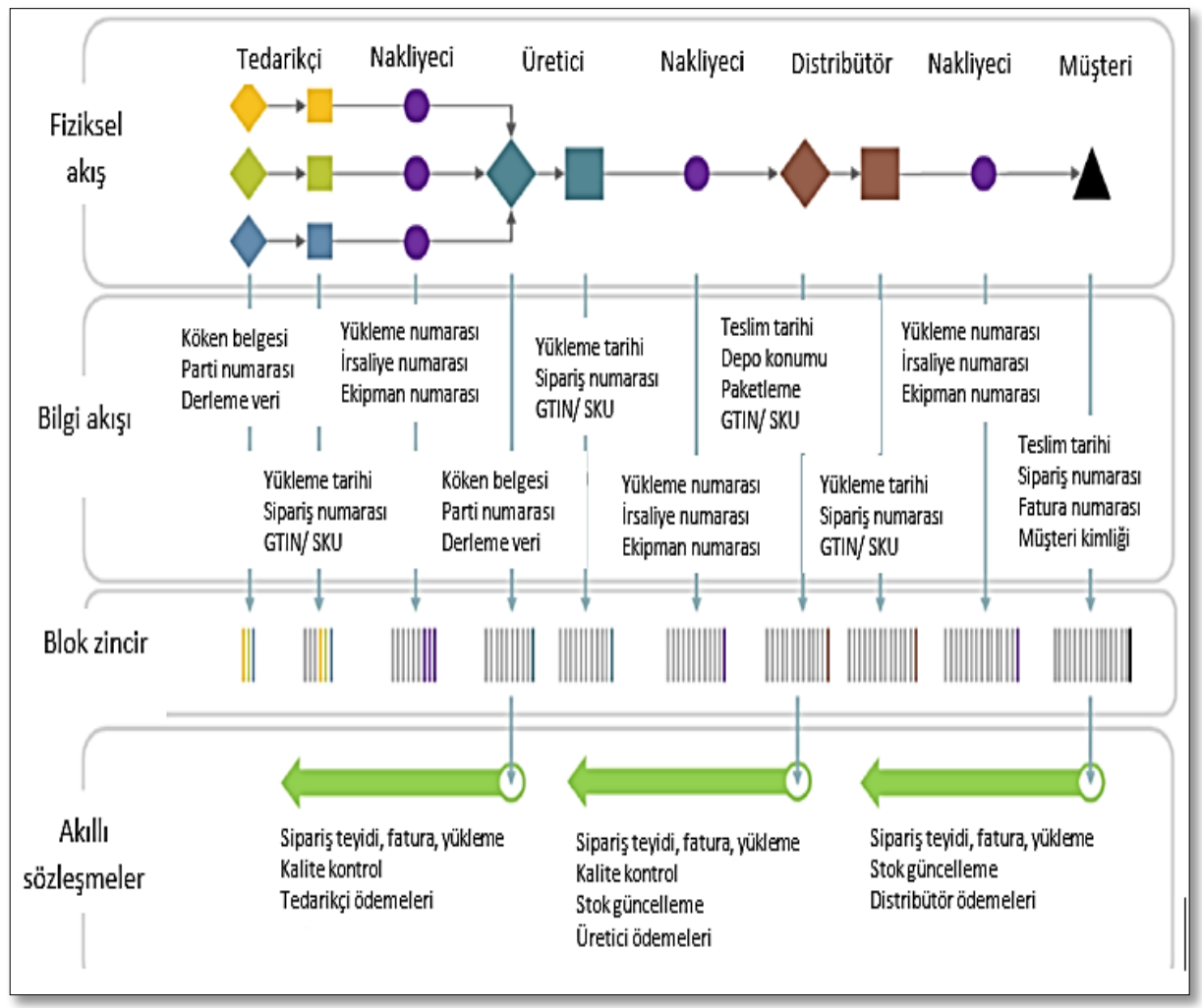

Şekil 3. Tedarik zincirinde blok zincir uygulamaları(Rodrigue, 2018, p. 22)

Şekil 3' de blok zincirin bir tedarik zinciri desteklemek için nasıl kullanılabildiği gösterilmektedir. Uygulama sürecinde fiziksel akış, bilgi akışı, blok zinciri ve akıllı sözleşmeler olmak üzere dört ana aşama bulunmaktadır:

- $\quad$ Fiziksel akışlar: Tedarikçilerden, üreticilere, distribütörlerden ve nihai müşterilere doğru işlemler ve hareketler dizinidir. Tesis (örneğin dağıtım merkezleri), modları ve terminallerini içermektedir.

- Bilgi akışları: Her tedarik zincirinde bilgi akışları mevcuttur. Örneğin, tedarikçiden parça siparişi veren bir üretici, bir Global Ticaret Madde Numarası (GTiN) veya Stok Tutma Birimi (Coşkun ve Tiryaki, 2011) için bir sipariş numarası oluşturur. Bu bilgiler, üretim bilgile- 
riyle ilişkilidir. Sonrasında, nakliyeci daha önce belirlenmiş ekipmanda (bir kamyon, bir konteyner, vb.) taşınan yük ile ilişkili bir sipariş ve sevkiyat numarası üretmektedir.

- Blok zinciri: Geçmişten bugüne kadar yukarıda belirtilen bilgi akışları, kimi zaman çeşitli bilgi sistemleri yoluyla, kimi zaman kâğıt formunda kimi zaman da işgücü kullanılarak yapılmaktadır. Ancak blok zincir ile tedarik zinciri boyunca bilgi ve fiziksel akış bloklara kaydedilmektedir. Bu bloklar birbiri ile bağlanarak tedarik zincirinin sonuna varıncaya kadar yapılan tüm görevleri, dahil olan tüm paydaşları ve bir müşteriye özel bilgileri içeren bir zincire dönüşmektedir.

- Akıllı sözleșmeler: Akıllı sözleşmeler, bir blok zincir içinde bulunan bilgileri kullanarak üzerine mutabık olunan sözleşmelerin otomatik olarak doldurulmasıyla oluşmaktadırlar. Akıllı sözleşmede, zincirde bulunan ilgili tarafların anlaşması olmadan herhangi bir değişiklik yapılması mümkün değildir. Örneğin, gerçekleşmiş olan bir teslimata dair tüm sözleşme şartları (örneğin miktar, kalite, zamanlama vb.) karşılandıktan sonra bir ödeme otomatik olarak gerçekleşmektedir (Rodrigue, 2018, s.23)

\section{Blok Zincir Uygulamasının Tedarik Zincirine Sağladı̆̆ı Yararlar}

Tedarik zinciri çok fazla sayıda ve çeşitte girdi ve çıktının olduğu, yine çok sayıda ve çeşitte paydaşın yer aldığı bir ağ olarak kompleks bir yapıdadır ve yönetilmesi oldukça güçtür. Bu nedenle de birçok sorunla karşılaşmaktadır. En sık yaşanan sorunlar; şeffaflığın olmaması, takip edilebilirliğin düşük olması, kaçakçllık, üründe ve/veya evrakta sahtecilik, yoğun evrak işleri, insan kaynaklı hataların yüksek oranda olması ve finansal işlemlerin takibidir. Bunların birçoğuna blok zinciri ile çözüm bulmak mümkündür.

- Şeffaflığın Sağlanması:Karşılaşılan sorunların en önemlilerinden bir tanesi yeterince şeffaflığın olmamasıdır. Bu durum ürünün izlenebilirliğini zorlaştırmaktadır (Voronchenko, 2017). Ancak blok zincir uygulaması ile tedarik zinciri yönetiminde yapılan tüm işlemleri RFID, barkod, otomatik kimlik tarayıcılar vs. yoluyla her aşamada eş zamanlı ve şeffaf olarak izlenebilmektedir (Kırbaş, 2018a, s.81). 
Örneğin, gıda sektöründe gida kaynaklı bir salgın söz konusu ise zincirde yer alan taraflar zararlı maddelerin nereden geldiğini, parti numaralarını, fabrika ve işleme verilerini, son kullanma tarihlerini, sevkiyat detayları ve hangi mağazalara teslim edildiğini görebilmektedir (Hackius ve Petersen, 2017).

- Takip Edilebilirliğin Artması: Tedarik zincirinde yer alan hammadde, malzeme, ürünün sadece son tüketicilere değil, tedarik zincirindeki süreçte bulunan paydaşların da bir sevkiyatın veya bir ürünün geldiği noktayı ve geçtiği süreçleri takip etmeleri oldukça önemlidir. Blok zincir, ürünün çıkış noktasından varış noktasına kadar doğru ve sabit bir kayıt sağlamaktadır. Böylece sondan başa doğru ürün ve süreç takip edilebilmektedir. Örneğin, ilaçların orijinal üreticiden alınması durumlarında ürünün, üreticinin ya da sürecin güvenilirliğini test etmek mümkün olmaktadır. Aynı şekilde gıda sektöründe de zincirdeki paydaşları akış hakkında bilgilendirmek için de kullanılmaktadır. Günümüzde kısıtlı teknolojiler nedeniyle çiftlikten çatala izlenebilirlik hala teori aşamasındadır. Blok zinciri bu teoriyi gerçeğe dönüştürme açısından büyük öneme sahiptir. Bir kayıp olması durumunda, süreç son sahibine kadar geri takip edilebilmekte ve tüm sürece tüm taraflar erişilebilmektedirler.

Ürün takip aşamasında özellikle üç uygulama dikkat çekmektedir. Bunlardan ilki bir maden firması BHP Billtondur. Bu firma tüm dünyada jeolojik numunelerin kaynağın takip etmek için bir uygulama yaratmışlardır. Son zamanlara kadar, örnekler tablolar ve e-postalar aracılığıyla takip edilirken artık, orijinal örnekleme konumu ve daha fazla işleme verileri Blok zincir tarafından kayıt altına alınmıştır. Bir diğer uygulama da bir şarap işletmesi tarafından yapılmaktadır. Bu işletme tüm sürecin adım adım takip edilmesi için blok zincir uygulamasına geçmiştir. Burada temel amaç, şarapta kaçakçılığın önüne geçilmesidir. Son firma ise $\mathrm{CBH}$ grup adında Avustralyalı bir tahıl ihracat işletmesidir. $\mathrm{CBH}$, ihraç edilen yulaf tanelerinin aslen Avustralya menşeili olduğunu kanttlayarak Asya'da rekabetçi bir avantaj kazanmayı hedeflemektedir (Petersen ve diğ., 2018).

\section{- Ü̈ründe velveya Evrakta Sahteciliğin, Horsizlığın ve Kaçakçılığın}

Önlenmesi:Tedarik zincirlerinin ikinci düzeyinden öteye daha alt tedarikçileri haritalamak ve takip etmek oldukça zordur. Bu sınırlı takip 
ise birçok detayın gözden kaçmasına ve güvenlik açılarının olmasına neden olmaktadır. Bu güvenlik açıkları sonucunda kaybolma, kaçakçlık, hırsızlık, sahte ürün taşımacılığı gibi yasal olmayan durumları yaratmaktadır (Madhwal ve Panfilov, 2017, s.1052).

Yüksek değerli öğelerin taklitleri yapılabilmekte ya da süreçler esnasında kaybedilebilmekte ve çalınabilmektedir. Örneğin, bir elmas, pahalı şaraplar, ilaçlar, saatler veya çantaların gerçek veya sahte olup olmadığını her zaman belirlemek kolay değildir. Ancak blok zincirle bu eşyalara dair tüm bilgiler kayıt altına alındığından bu bilgileri teyit etmek mümkün olmaktadır (Hackius ve Petersen, 2017,s.8)

- Evrak Isşlerinde Kolaylık:Nakliye sürecinde çok fazla evrak işlemi yapılmaktadır. Bu işlemler hem zaman hem de para kaybına neden olmaktadır. Yapılan ticaret ile ilgili evrak işleme maliyetinin fiziksel taşıma maliyetlerinin yüzde 15 ile 50'sini oluşturduğu tahmin edilmektedir. Örneğin, birçok işletme hala kâğıt üzerine basılı konşimento kullanmaktadırlar. Bu durum, lojistik hizmet sağlayanların örgüt yapıları içinde evrakları düzenleyen bir departman ve burada çalışan personel ihtiyacı doğurmaktadır. Blok zincir ile işletmelerin basılı evrak gereksinimi ortadan kalkacağından, konşimento ya da dokümantasyon departmanlarının varlıkları da son bulacaktır (Hackius ve Petersen, 2017; Yildız ve Baştuğ, 2018).

- Finansal Faaliyetlerde Kolaylı:Ödemelerin gecikmesi, sürecin aksamasinin temel nedenlerinden biridir. Blok zincir teknolojisinde var olan akıllı sözleşmeler sayesinde ödemeler daha hızlı yapılabilmekte, işlem maliyetleri daha düşük olmakta ve dolandırıcılık riski ortadan kalmaktadır (Francis, 2018; Rodrigue, 2018)

- İnsan Kaynaklı Hataların Azalması :İşletmeler her ne kadar sözleşme koşullarına uygun bir biçimde faturaların, gönderi ve teslim belgelerinin hatasız bir biçimde hazırlanması konusuna büyük özen gösterseler de tedarik zinciri çok fazla süreç ve işlemden oluştuğundan evrakların kaybedilmesi, yanlış düzenlenmesi, işlemsel hatalar vs. çok sık yaşanmaktadır. Ancak blok zincir uygulamaları herhangi bir manuel işlem gerektirmediğinden büyük ölçüde insan kaynaklı hatalar azalmaktadır (Tian, 2016). 
Blok zincir uygulamasında bir işlem girildiğinde blok zincir sözleşme kodu çalışmaya başlamaktadır. Eğer işlem sözleşmede bulunuyor ise hemen yazılmakta ve fatura anında ödenmektedir. Eğer ilgili fatura mükerrer ise sözleşmeye bakılmakta ve doğrulanmamış ise kayda alınmamaktadır. Faturanın yanlış yazılması durumunda ise doğrulama, blok zincir ağı içinde otomatik olarak gerçekleştirilmektedir. Sonuç olarak bu uygulama ile artık şüpheli, yanlış veya kayıp faturalar söz konusu olmamaktadır (Francis, 2018).

\section{Blok Zincir ile İlgili Yapılmış Önceki Çalışmalar}

Finans alanındaki uygulamalarıyla tanınan blok zinciri ile ilgili yapılan çalışmalar, bu teknolojinin finans alanına ek olarak farklı birçok alanda da uygulanabilir olduğu görüldükçe artmış ve çeşitlenmiştir. Bunları özetlemek gerekirse;

- Blok zincirin ilk başlarda Bitcoin (kripto para) ile ilgili bir kavram olarak ortaya çıkması nedeniyle çalışmalar ağırlıklı olarak finans alanında yapılmıştır. Bu çalışmalarda kripto paraların yönetim biçimi irdelenerek, zayıf yönleri ve güvenliğinin sağlanmasına yönelik yapılması gerekenler vurgulanmıştır (Anish, 2014; Back, vd., 2014; Barkatullah ve Hanke, 2015; Bitcoin Theft, 2013; Edwards, 2015; Eyal vd., 2016; Feld vd.,2014; Gipp vd., 2016; Greebel vd., 2014; Moser vd., 2013; Nakamato, 2008; Ølnes, 2016; Omohundro, S., 2014; Roth, 2015; Tsukerman, 2015; UK Government, 2016; Underwood, S., 2016; Wörner vd., 2016; Ziegeldorf vd., 2015).

- Blok zincirle ilgili diğer bir çalışma alanı ise bilgisayar teknolojilerine yöneliktir (Coeckelbergh ve Reijers, 2015; Di Battista vd.,2015; Kishigami vd., 2015; Luu vd., 2015; Maxwell vd., 2015; Network Security, 2013; Swan, 2015; van den Hoof vd., 2014; Zhang ve Wen, 2015; Zyskind vd., 2015).

- İzlenebilirlik özelliğinin öne çıkması ile tedarik sürecinde bozulma, çalınma ya da sahtecilik riski taşıyan gıda, ilaç, tehlikeli madde, hassas elektronik cihaz gibi ürünlerin takibine yönelik tedarik zincirindeki uygulamalara da fayda sağlayacağ görülmüş, bu konuda çok çeşitli çalışmalar yapılmıştır (Jabbar ve Bjørn, 2018; Ruta vd., 2017; Swanson vd., 2017; Treiblmaier, H. 2018; Zu ve Kaynak, 2012; Archa vd., 2018; 
Bocek vd., 2017; Imeri ve Khadraoui, 2018; Kshetri, 2017; Liu vd., 2017; Mackey ve Nayyar, 2017; Madhwal ve Panfilov, 2017; Markets ve Markets, 2016; Tian, 2016; Tse vd., 2018) .

- Bu alanların dışında kalan ve sektörel ya da faaliyete yönelik olmayan çalışmalar da literatürde yer almaktadır (Bradbury, 2014; DeWaal ve Dempsey, 2015; Francisco ve Swanson, 2018; Hofmann vd., 2018; Kim ve Laskowski, 2018; Liv d., 2017; Lu ve Xu, 2017; Smetana vd., 2018)

- Türkiye'de ise eğitim, işletmecilik, bilişim, sağlık gibi çok farklı çalışmalar bulunmaktadır (Altunbaşak, 2018; Ayberkin, 2018; Durğay ve Karaarslan, 2018; Karaarslan ve Akbaş, 2017; Akben ve Çinar, 2018; Kırbaş, 2018b; Mermer; Ünsal ve Kocaoğlu, 2018a; H. Yıldırım, 2018; Yıldız ve Baştŭg, 2018).

Küreselleşmenin yarattığ 1 ticaret anlayışı, çeşitli ve yeni çözümler ürettiği gibi çeşitli sorunlara neden olmaktadır. Tüm dünya genelinde farklı lokasyonlardan daha kolay hammadde tedarik edilebilme, yeni pazarlara daha rahat erişim imkanı, teknolojik gelişmelerin varlığı gibi çözümlerin olmasının yanı sıra; özellikle küreselleşme ile tedarik zincirlerinin oldukça uzun ve karmaşık hale gelmesiyle denetiminin ve izlenebilirliğinin zorlaşmasına, kötü niyetli insanlara fırsat doğmasına, rekabetin daha da yoğunlaşmasına vs. de yol açmaktadır. Bu konunun incelenmesinin ve tartışmasının daha uzun zaman süreceği düşünülmektedir.

$\mathrm{Bu}$ çalışmada oldukça yeni olan, uygulama çeşitleri henüz yeterince net olmayan blok zincir teknolojisinin, tedarik zinciri yönetimine faydalarının ne olabileceği sorularına yapılan literatür taraması ile cevap bulunması, bu cevaplarla diğer çalışmalara katkı sunulması ve konu ile ilgili literatürdeki bazı eksik noktaların tamamlanması amaçlanmaktadır.

\section{Sonuç}

2008 yılında sanal para birimi Bitcoin kavramı ile birlikte başlayan, bilinirliği gittikçe artan ve sektörel bazda yaygınlaşmaya başlayan blok zinciri teknolojisi; reel dünyada yer alan para, ürün veya bilgi gibi çeşitli değerlerin değiş tokuş yapıldı̆̆ı; herhangi bir merkezi yapıya bağlı olmayan ve süreçte yer alan tüm paydaşlar tarafından izlenebilen bir yapıdır. 
Sanal para sisteminin günümüze kadar sağlam bir biçimde gelebilmesinin ana nedeni olan blok zinciri (Blockchain) teknolojisinin en dikkat çeken avantajı çok yüksek seviyelerde güvenlik garanti etmesidir. Blok zincirde yapilan her bir hesap hareketi kaydedilmekte; aynen korunabilmesi için dijital olarak imzalanmakta ve bir ağ üzerinden dağıtılmaktadır. Sistemde yeni bir hesap hareketi olduğunda daha önceden belirlenmiş bir algoritma ile bu yeni kaydın doğruluğu teyit edilmektedir. Eğer ilgili kaydın doğruluğu onaylanıyorsa, yeni bir blok zinciri sisteme dahil olmakta; aksi halde ise, bu hesap hareketi sisteme dahil olmamaktadır. Bu nedenle de üzerinde izinsiz değişiklik yapmak mümkün olmamaktadır.

Bir diğer avantajı ise eş zamanlı izlenebilirlik sağlamasıdır. RFID (radyo frekans tanımlama sistemi) ile koordineli uygulanan bu teknoloji sayesinde ürünlerin çıkış noktasından varış noktasına kadar ki tüm adımları eş zamanlı kayıt altına alındığından eş zamanlı görüntülemek, izlemek ve takip etmek mümkün hale gelmektedir. Özellikle de gıda, ilaç, kimyasal madde, elektronik cihazlar ve değerli maden ürünlerinin izlenebilir olması hem üreticiler hem lojistikçiler hem de tüketiciler açısından büyük fayda sağlamaktadır. Bu da sistemde sahtekarlık yapılması ihtimalinin azalması sonucunu doğurmaktadır.

Blok zincirin sağladığı bir başka avantaj ise; bir merkezi otoriteye bağlı olmamasıdır. Bu durum işlemlerin daha hızlı bir şekilde yürümesine ve maliyetlerin daha düşük olmasına imkân tanımaktadır. Ancak bu avantaj beraberinde dezavantajlara da zemin hazırlamaktadır. Çünkü bir yere bağlı olmadan çalışan bu sistem, çok çeşitli yazılımcılar tarafından, değişik amaçlar için farklı şekillerde yapılandırılabilmektedir. Bu da zincirlerin standart olmaması ve zincir üyelerinin herhangi bir sorun yaşaması durumunda muhatap olmadığı için bunları kolayca çözememesi anlamına gelmektedir. Yatırımciların blok zincir uygulamalarına daha temkinli yaklaşmalarının altında yatan temel neden budur. Ancak bu sorunun çözümü için IBM, Cisco, Fujitsu gibi büyük teknoloji firmaları ve J.P. Morgan, Accenture gibi finans kuruluşları, çeşitli blok zinciri uygulamalarını bir çatı altında toplamak için bir konsorsiyum kurmuşlardır (https://bkm.com.tr/blok-zinciri-blockchain-nedir/).

Blok zincir teknolojisine uyum sağlayabilmek için hem yüksek yatırıma ihtiyaç duyulması hem de geleneksel yapıda radikal bir biçimde de- 
ğişiklik yapılması gerekeceğinden şimdilik her sektör veya işletme tarafından uygulanabilirliğinin zor olduğu görülmektedir. Sadece Accenture, Cisco, Intel, IBM, Block Stream, Bloomberg, Gem gibi çok büyük bazı kurumlar ya da kimya sanayi işletmesi BASF, Finansal teknoloji girişimi Quantoz ve Hollandalı girişim Ahrma üçlüsü; IBM, Ticari girişim Tragura, ve yatırım bankası Natixis ortaklığı gibi işbirlikleri tarafından uygulanmaya başlanmıştır. Ayrıca ABD, İsviçre, Estonya, Dubai, İngiltere, Singapur, Kıbrıs gibi çeşitli ülkelerde kamusal alanda blok zinciri teknolojisine yönelik yatırımlar yapılmaktadır. Blok zincir teknolojisi ile ilgili henüz yeterince aktif olmayan Türkiye dahil birçok farklı ülkede de (ağırlıklı olarak kripto paralara yönelik olsa da) bu konuda bazı çalışmalar yürütülmektedir (Ekİn, 2018; Petersen et al., 2018; Ünsal \& Kocaoğlu, 2018b). Ancak bu teknolojinin yaygınlaşacağ 1 ve maliyetinin zamanla düşeceği düşüncesiyle önümüzdeki yıllarda daha çok sektörde ve uygulama alanlarında kullanılacağı öngörülmektedir.

Tedarik zinciri yönetim faaliyetlerine olan potansiyel etkileri hakkında hala yeterli bilginin olmadığı blok zinciri teknolojisinin daha iyi anlaşılabilmesi adına, sektörün en önemli sorunlarını belirlemek ve gerekirse lojistik sektörü yararına çözümler tasarlamak için çok daha çeşitli metodolojik yaklaşımlar ve ampirik çalışmaların yapılması gereklidir. Zira oldukça yeni olan bu teknolojiye gerek birçok uygulamanın henüz pilot çalışma aşamasında olması gerekse yatırım maliyetlerinin yüksek olması gerekse de eksik yönlerini bulunması nedeniyle tedbirli yaklaşılmaktadır. Bu da bu konuda yapılması planlanan çalışmalar için en büyük kısıt olarak karşımıza çıkmaktadır. Bu kısıtın önüne geçilebilmesi adına akademisyenler ve uygulayıcılar arasında yakın bir iş birliği sağlanması gerekmektedir. Ancak o zaman bilimsel ve sektörel açılardan karşılıklı fayda sağlanacak ve uygulamalar daha net sonuçlar verecektir. 


\section{EXTENDED ABSTRACT}

\section{Blockchain Technology and Its Applications in Supply Chain Managements}

İsmail Bakan - Zümrüt Hatice Şekkeli

Kahramanmaraş Sutcu Imam University

Even though the definition of blockchain is unclear, it can be defined as a chain of blocks that contains its own and the previous one's information; in an encrypted, periodically, chronologically format for each activity in the process (Mattila, 2016, s.6; Tian, 2016). By other words, it can be considered as a distributed digital ledger, which contains back-linked information blocks, where each block is identified by a cryptographic signature. The main benefits of this technology for all businesses and industries are immutable records, traceability and transparency along the chain (Jacobovitz, 2016, p.2). Additionally, this technology guarantees the integrity of data except for the necessity of a trustful third party (Tribis, et.al. 2018, p.1).

Blockchain technology is based on three key elements. They are autonomy, verifiability and invariable. Autonomy means having a network structure that operates with a trust-based infrastructure and is walking with the membership system without relying on any authority (www.elektrikport.com/); Verifiability means that all members have private passwords and use these passwords to be able to operate on the network. Therefore, only those who have the password can log into the network. However, if members want, they can remain anonymous. Invariance is a compromise-based algorithm of the software, and members on the network can verify per transaction in the respective block (Hackius ve Petersen, 2017, p.6-7).

The Blockchain which is mentioned in 2008 at Satoshi Nakamoto's Bitcoin white paper (Jacobovitz, 2016, p.2), is initially invented to ensure the security of the electronic currency Bitcoin System at financial areas. But nowadays it has been started to use at different various are-as 
(Hackius \& Petersen, 2017, p.5) as social and legal industries, smart property, supply chain networks etc. The application logic of block-chain and supply chains, in particular, is of great similarities (Rodrigue, 2018).

The supply chain is a structure of many physical flows, information flows and including multiple actors and stakeholders. In this structure, starting from the receipt of the order of the right product, the right amount, right conditions, in the right position and time to transmit many activities are done (Lai ve Cheng, 2016). the supply chain has a very important role for all industrial sector, which distributes many types of products globally, from any manufacturer to another manufacturer or any consumer. if it is managed with the right methods and properly, it provides to grow the company, increase the rate of profit, reduce costs and increase customer satisfaction (Ungan, 2011, p.308).

Unfortunately, managing supply chains are very difficult due to there are multiple actors and stakeholders, which are interacting each other, to fulfil their function (right product, quantity, condition, location, customer, cost and time) for each physical flow and information flows (Rodrique, 2018, s.22). This complexity causes many problems. The most common problems are; lack of transparency, inadequate traceability, smuggling, counterfeiting in the product and/or paperwork, heavy paperwork, a high proportion of human errors and the pursuit of inaccurate financial transactions. For all of these problems, blockchain technology offers solutions.

- All processes made in supply chain management can be monitored simultaneously and transparently through RVD, barcode, automatic identity scanners etc.,

- A correct and stable record can be provided from the output point of the product to the destination,

- Fraud or theft may be prevented in the product or in the document, as the process can be traced back to the last owner when there is any problem,

- Paperwork is easier and human-induced errors are reduced because there is no need for manual processing and printed documents,

- By virtue of faster payments, lower transaction costs and eliminated fraud risk, financial activities become easier by smart contracts. 
Blockchain technology has not yet enough work and knowledge about its impacts on supply chain management activities. But considering the features, at the future, it is thought that this technology will be used more widely in tracking the movements of products, that carry the risk of deterioration, theft or counterfeiting etc. as food, pharmaceuticals, hazardous substances, sensitive electronic devices along the supply chain.

This study aims to contribute to literature about applications of blockchain technology at supply chain management processes in theoretically. For this purpose, the national and international literature such as books, magazines, theses, Internet resources etc. was scanned and compiled.

In the study, the definition, structure, functioning benefits, types and application areas of blockchain technology are described in the conceptual framework. And then the applications of blockchain technology on the supply chain, the benefits of supply chain management are information about the studies made in this regard. The final chapter also includes a summary of the findings and a summary assessment.

\section{Kaynakça / References}

Akben, İ. ve Çinar, S. (2018). Lojistik ve tedarik zinciri yönetiminde Blockchain: Vaatler, uygulamalar ve engeller. Anadolu I. Uluslararasi Multidisipliner Çalişmalar kongresi, 2018, Diyarbakır.

Altunbaşak, T. A. (2018). Blok zincir (Blockchain) teknolojisi ile vergilendirme. Maliye Dergisi, 174, 360-371.

Anish Dev, J. (2014). Bitcoin mining acceleration and performance quantification. In Proceedings (1-6), IEEE 27th Canadian Conference on Electrical and Computer Engineering. 4-7 May, Toronto, Canada.

Archa, B. Alangot ve Achuthan, K. (2018). Trace and track: Enhanced pharma supply chain infrastructure to prevent fraud, Lect. Notes Inst. Comput. Sci. Soc.-Inform. Telecommun. Eng. LNICST, 218, 189195.

Avunduk, H. ve Aşan, H. (2018). Blok zinciri (Blockchain) teknolojisi ve işletme uygulamaları: Genel bir değerlendirme. Dokuz Eylul Universitesi Iktisadi ve Idari Bilimler Dergisi, 33(1), 369-384. doi:10.24988/deuiibf.2018331746 
Babacan, M. (2003). Lojistik sektörünün ülkemizdeki gelişimi ve rekabet vizyonu. Ege Akademik Bakış, 3(1), 8-15.

Back,A. G., Maxwell, M., Corallo, M., Friedenbach,İsim. and L. Dashjr.(2014). Enabling blockchain innovations with pegged sidechains. URL: http://www. opensciencereview. com/papers/123/enablingblockchain-innovations-with-peggedsidechains, 72.

Badzar, A. (2016). Blockchain for securing sustainable transport contracts and supply chain transparency:An explorative study of blockchain technology in logistics. Department of Service Management and Service Studies. Lund University, Department of Service Management and Service Studies, SMMM20, Masters Thesis, Helsingborg, Sweden

Bakan, İ., ve Şekkeli, Z. H. (2017). Lojistik yönetimi. İstanbul: BETA yayınevi, 1 . basım.

Barkatullah, J. ve Hanke, T. (2015). Goldstrike 1: CoinTerra's first-generation cryptocurrency mining processor for Bitcoin. IEEE, 35, 68-76.

Barutçu, S. (2007). İnternet tabanlı tedarik zinciri yönetimi:Denizli tekstil işletmelerinin internet tabanlı tedarik zinciri yönetiminden yararlanma durumuna yönelik bir araştırma. Selçuk Üniversitesi Sosyal Bilimler Enstitüsü Dergisi, 18, 133-150.

Bilginer, N., Kayabaşı, A. ve Sezici, E. (2008). Lojistik faaliyetlerin süreçsel etkinliğine etki eden faktörlerin değerlendirilmesi üzerine ampirik bir çalışma. Dumlupınar Üniversitesi Sosyal Bilimler Dergisi, 22, 277295.

Bitcoin Theft. (2013). Massive Bitcoin thefts and seizures leave many users nervous and poorer. Computer Fraud \& Security, 12, 3.

Bocek, T., Rodrigues, B.B., Strasser T., and Stiller B., (2017). Blockchains everywhere - A use-case of blockchains in the pharma supplychain, in the Proceedings (772-777) .IM 2017 - 2017 IFIP/IEEE International Symposium on Integrated Network and Service Management, 8-12 May, Lisbon, Portugal.

Bowersox, D. J., Closs, D. J., ve Cooper, M. B. (2002). Supply chain logistics management, McGraw-Hill New York, NY.

Bradbury, D. (2014). Anonymity and privacy: A guide for the perplexed. Network Security, 10, 10-14. 
Coeckelbergh, M., ve Reijers, W. (2015). Cryptocurrencies as narrative technologies. ACM SIGCAS Computers and Society - Special Issue on Ethicomp, 45(3), 172-178.

Coşkun, E., ve Tiryaki, E. N. (2011). Tartışmacı metin yapısı ve öğretimi. Mustafa Kemal Üniversitesi Sosyal Bilimler Enstitüsü Dergisi, 8(16), 63-73.

Crosby, M. (2015). Google, Nachiappan, Yahoo, Pradhan Pattanayak, Yahoo, Sanjeev Verma, Samsung Research America \& Vignesh Kalyanaraman, Fairchild Semiconductor, BlockChain Technology Beyond Bitcoin. Sutardja Center for Entrepreneurship \& Technology Technical Report.

Çelenk, B. V., (2017). Akıllı sözleşmeler (Smart Contracts) nedir?, 22 Aralık 2018 tarihinde https://startuphukuku.com/akilli-sozlesmelersmart-contracts-nedir/ adresinden erişildi .

DeWaal, G., ve Dempsey, G. (2015). New York BitLicense regulations virtually certain to significantly impact transactions in virtual currencies. Journal of Investment Compliance, 16(4), 59-65.

DiBattista, G., Di Donato, V., Patrignani, M., Pizzonia, M., ve Roselli, V. (2015). Bitcoinview: Visualization of flows in the Bitcoin transaction graph. InProceedings (1-8) IEEE Symposium on Visualization for Cyber Security, 31 May, Chicago, IL, USA.

Dik, A. (2015). Peer to peer (P2P) ağlar nedir ve nasıl çalışır?, 15 Eylül 2018 tarihinde https://www.elektrikport.com/makale-detay/peer-topeer-(p2p)-aglar-nedir-ve-nasil-calisir/15406\#ad-image-0 adresinden erişildi.

Doruk, A. M. B. ve Özen, Ü. (2018). Blok zinciri ile gerçek zamanlı doğrulanabilir eğitim belgeleri. İktisadi Yenilik Dergisi, 5(2), 75-82.

Dönmezgel E., Corda: Açık Kaynak Özel Dağıtık Defter; 22 Mart 2018 tarihinde https://blockchaindanismanlik.com/corda-acik-kaynakozel-dagitik-defter/ adresinden erişildi.

Dönmezgel E., Hayatımızı Değiştirecek Blockchain Uygulamaları; 22 Mart 2018 tarihinde https://bitcoinlerim.com/blockchain-uygulamalarikullanim-alanlari/ adresinden erişildi.

Durğay, Z. ve Karaarslan, E. (2018). Blokzinciri Teknolojisinin E-Devlet Uygulamalarında Kullanımı: Ön İnceleme. Akademik Bilişim Konferans1, Karabük. 
Edwards, C. (2015). Finance - Bitcoin price crash finds new victims. Engineering and Technology, 10, 19.

Ekin, A. ve Ünay, D. (2018). Blockchain applications in healthcare.26th Signal Processing and Communications Applications Conference (SIU). IEEE, 2-5 May, İzmir, 2018.

Eyal, A. E. Gencer, E. G. Sirer, ve Van Renesse R. Bitcoin-NG: A scalable blockchain protocol In 13th \{USENIX\} Symposium on Networked Systems Design and Implementation (\{NSDI\} 16) (pp. 45-59).

Feld, S., Schonfeld, M., ve Werner, M. (2014). Analysing the deployment of Bitcoin's P2P network under as AS-level perspective. Procedia Computer Science, 32, 1121-1126.

Francis, J. (2018). Closing The Hall Of Mirrors, How Blockchain Will Simplify And Transform The Suppy Chain. Copyright (C 2018 Accenture Consulting.

Francisco, K. \& Swanson, D. (2018)., The supply chain has no clothes: Technology adoption of Blockchain for supply chain transparency, Logistics, 2(1), 2.

Gipp, B., Kosti, J. ve Breitinger, C. (2016, September). Securing video integrity using decentralized trusted timestamping on the Bitcoin Blockchain. Mediterranean Conference on Information Systems (51). http://aisel.aisnet.org/mcis2016

Greebel, E. L., Moriarty, K., Callaway, C. ve Xethalis, G. (2014). Recent key Bitcoin and virtual currency regulatory and law enforcement developments.Journal of Investment Compliance, 16(1), 13-18.

Hackius, N., ve Petersen, M. (2017). Blockchain in logistics and supply chain: Trick or treat, In Proceedings (8-13). Hamburg International Conference of Logistics (HICL), 112-13 October, Hamburg.

Hofmann, U. M. S., and Bosia, N. (2018) Why to pay attention on Blockchain-driven supply chain finance?, Supply Chain Finance and Blockchain Technology, Springer, 1-6.

Imeri, A. ve Khadraoui, D. (2018). The security and traceability of shared information in the process of transportation of dangerous goods, in 9th IFIP International Conference on New Technologies, Mobility and Security (NTMS), (1-5), 2018, 02 April, Paris.

İslamoğlu, A. H., ve Alnıaçık, Ü. (2014). Sosyal bilimlerde araştirma yöntemleri. Içinde (511). İstanbul: Beta Yayınevi. 
Jabbar, K. ve Bjørn,P. (2018).Infrastructural grind: Introducing Blockchain technology in the shipping domain, in Proceedings (297-308), ACM Conference on Supporting Groupwork, 2018, New York, NY, USA,

Jacobovitz, O. (2016). Blockchain for identity management. Technical Report, The Lynne and William Frankel Center for Computer Science Department of Computer Science, Ben-Gurion University, Beer Sheva, Israel.

Karaarslan, E., ve Akbaş, M. F. (2017). Blok zinciri tabanlı siber güvenlik sistemleri, Uluslararasi Bilgi Güvenliği Mühendisliği Dergisi, 3(2) 1621.

Kırbaş, İ. (2018). Blokzinciri teknolojisi ve yakın gelecekteki uygulama alanları. Mehmet Akif Ersoy Üniversitesi Fen Bilimleri Enstitüsü Dergisi, 9(1), 75-82.

Kim, H. M. ve Laskowski, M. (2018). Toward an ontology-driven blockchain design for supply-chain provenance. Intelligent Systems in Accounting, Finance and Management, 25(1), 18-27.

Kishigami, J., Fukimura, S., Watanabe, H., Nakadaira, A. ve Akutsu, A.(2015). The blockchain-based digital content distribution system.In Proceedings (187-190) IEEE 5th International Conference on Big Data and Cloud Computing, 26-28 August, Dalian, China.

Kshetri, N. (2018). 1 Blockchain's roles in meeting key supply chain management objectives, Int. J. Inf. Management, 39, 80-89,

Kushch, S. ve Prieto Castrillo, F. (2017). A review of the applications of the Block-chain technology in smart devices and dis-tributed renewable energy grids. ADCAIJ: Advances in Distributed Computing and Artificial Intelligence Journal, 6(3), 75. doi:10.14201/adcaij2017637584

Kuzuloğlu, S. (2016). Blok zinciri (Blockchain) nedir?, 15 Ocak 2012 tarihinde https://bkm.com.tr/blok-zinciri-blockchain-nedir/ adresinden erişildi

Lai, K.H. ve Cheng, T. E. (2016). Just-in-time logistics. Routledge.

Li, H., Wu, B., King, Z. B., Miled, J., Wassick, J.. ve Tazelaar, J. (2017). On the integration of event-based and transaction-based architectures 
for supply chains, in Proceedings (pp. 376-382), IEEE 37th International Conference on Distributed Computing Systems, 5-8 June, Atlanta, GA, USA.

Liu, S. S., Zhu, Mundie, T., ve Krieger, U., (2017). Advanced block-chain architecture for e-health systems, in proceedings (1-6), 2017 IEEE 19th International Conference on e-Health Networking, Applications and Services (Healthcom), 2017, Dalian, China.

Lu, Q. ve Xu, X. (2017). Adaptable Blockchain-based systems: A case study for product traceability, IEEE Software,34, 6, 21-27.

Luu, L., Teutsch, J., Kulkarni, R., ve Saxena, P. (2015). Demystifying incentives in the consensus computer. CCS '15: Proceedings of the 22nd ACM SIGSAC Conference, October 12 - 16, Denver, Colorado, USA .

Mackey, T. K. ve Nayyar, G. (2017). A review of existing and emerging digital technologies to combat the global trade in fake medicines. Expert Opinion on Drug Safety 16(5), 587-602.

Madhwal, Y. ve Panfilov, P. (2017). Blockchain And Supply Chain Management: Aircrafts' Parts' Business Case. In Proceedings (10511056), 28th DAAAM International Symposium, Vienna, Austria, 23 26 October. doi:10.2507/28th.daaam.proceedings.146

Markets ve Markets (2016), Blockchain market by provider, application (payments, exchanges, smart contracts, documentation, digital identity, clearing and settlement), organization size, vertical, and region: Global forecast to 2021, Market Report, 01.02.2019. tarihinde www.MarketsandMarkets.com adresinden erişildi.

Mattila, J. (2016). The blockchain phenomenon- the disruptive potential of distributed consensus architectures. ETLA Working Papers ,38, 15 Ocak 2018 tarihinde http://pub.etla.fi/ETLA-Working-Papers-38.pdf. adresinden erişildi

Maxwell, D., Speed, C. ve Campbell, D. (2015). 'Effing' the ineffable: Opening up understandings of the blockchain. In British HCI '15: Proceedings (208-209) , British HCI Conference, 2015, Lincoln, Lincolnshire, United Kingdom.

Mermer, G. B. (2018). Blok zincir teknolojilerine genel bir bakış prensibi, firsatlar1 ve zorlukları. 26th Signal Processing and Communications Applications Conference (SIU). IEEE, 2018, İzmir. 
Moser, M., Bohme, R., ve Breuker, D. (2013). An inquiry into money laundering tools in the Bitcoin ecosystem. eCrime Researchers Summit, $1-14$.

Nakamoto, S. (2008). Bitcoin: A peer-to-peer electronic cash system, accessed 12 August 2017: https://bitcoin.org/en/bitcoin-paper

Network Security (2013). In brief network security, 11, 3.

Ølnes, S. (2016, September). Beyond bitcoin enabling smart government using blockchain technology. In International Conference on Electronic Government and the Information Systems Perspective (253-264). Springer, Cham.

Omohundro, S. (2014). Cryptocurrencies, smart contracts, and artificial intelligence. AI Matters, 1, 19-21. ACM New York, NY, USA

Petersen, M., Hackius, N., ve Von See, B. (2018). Mapping the sea of opportunities: Blockchain in supply chain and logistics it, Information Technology, 60(5-6), 263-271. doi:10.1515/itit-2017-0031

Rodrigue, J.-P. (2018). Efficiency and sustainability in multimodal supply chains, International Transport Forum Discussion Paper, No. 2018-17, Organisation for Economic Co-operation and Development (OECD), International Transport Forum, Paris, http://dx.doi.org/10.1787/12f93f71-en

Roth, N. (2015). An architectural assessment of Bitcoin: Using the systems modelling language. Procedia Computer Science, 44, 527-536.

Ruta, F., Scioscia, S., Ieva, G., Capurso, E., Di Sciascio, F. (2017).Supply chain object discovery with semantic-enhanced Blockchain, in Proceedings (60:1-60:2) 15th ACM Conference on Embedded Network Sensor Systems, 2017, New York, NY, USA.

Serdar (2018). Blockchain ve Bitcoin, Ethereum Ripple Farkı, 15 Nisan 2018 tarihinde https://sirazduvari.com/blockchain-ve-bitcoinethereum-ripple-farki/ adresinden erişildi

Smetana, S., Seebold, C. ve Heinz, V. (2018). Neural network, blockchain, and modular complex system: The evolution of cyber-physical systems for material flow analysis and life cycle assessment, Resour. Conserv. Recycl., 133, 229-230.

Swan, M. (2015). Blockchain thinking: The brain as a decentralized autonomous corporation. Technology and Society Magazine, 34(4), 41-52. 
Swanson, D., Goel, L., Francisco, K., ve Stock, J. (2017). Applying theories from other disciplines to logistics and supply chain management: a systematic literature review. Transportation Journal, 56(3), 299356.

Tian, F. (2016). An agri-food supply chain traceability system for china based on RFID \& Blockchain technology. Service Systems and Service Management (ICSSSM), 13th International Conference on. IEEE, 24-26 June, Kunming, China.

Treiblmaier, H. (2018), Optimal levels of (de)centralizationfor resilient supply chains, The International Journal of Logistics Management, 29 (1), 435-455.

Tribis, Y., El Bouchti, A., Bouayad, H., ve El Ghazi, H. (2018). Supply chain management based on Blockchain: A systematic mapping study. MATEC Web of Conferences, vol. 200, p. 20 doi:10.1051/matecconf/201820000020

Tse,D., Zhang, B. , Yang,Y., Cheng, C. ve Mu, H. (2018). Blockchain application in food supply information security, in proceedings (13571361) the IEEE International Conference on Industrial Engineering and Engineering Management, 2017-December, Singapore, Singapore.

Tsukerman, M. (2015). The block is hot: A survey of the state of bitcoin regulation and suggestions for the future. Berkeley Technology Law Journal, 30, 1127-1169.

TUBITAK (2017). Blokzincir teknolojiler, 15 Ocak 2019 tarihinde http://blokzincir.tubitak.gov.tr/blok-zincir.html adresinden erişildi.

UK Government (2016). Distributed ledger technology:Beyond block chain, Report by the UK Government Chief Scientific Advisor, GovernmentOffice for Science, London.

Underwood S., (2016). Blockchain beyond bitcoin. Commun ACM 59, 11 , $15-17$

Ungan, M. C. (2011). En iyi tedarik zinciri uygulamaları ve bir saha çalışması. Süleyman Demirel Üniversitesi İktisadi ve İdari Bilimler Fakültesi Dergisi, 16(2), 307 - 322.

Ünsal, E., ve Kocaoğlu, Ö. (2018). Blok zinciri teknolojisi: Kullanım alanları, açık noktaları ve gelecek beklentileri. Avrupa Bilim ve Teknoloji Dergisi, 13, 54-64. doi:10.31590/ejosat.423676) 
Van den Hooff, J., Kaashoek, M. F., ve Zeldovich, N. (2014). VerSum: Verificable computations over large public logs. In CCS '14: Proceedings (1304-1316). ACM SIGSAC Conference on Computer and Communications Security, 2014, Scottsdale, Arizona, USA

Voronchenko, K. (2017). Do you need a Blockchain? Supervised by Ivo Kubjas. 22 Ocak 2019 tarihinde https://courses.cs.ut.ee/MTAT.07.022/2017_fall/uploads/Main/kyrylo-report-

f17.pdf adresinden erişildi .

Wörner, D., Von Bomhard, T., Schreier, Y. P., ve Bilgeri, D. (2016). The Bitcoin ecosystem: Disruption beyond financial services?

Wu, Z. Li, B. King, Z. B. Miled, J. Wassick, J. Tazelaar,(2017). A distributed ledger for supply chain physical distribution visibility, Inf. Switz., 8(4), 1-18.

Wüst, K., ve Gervais, A. (2017). Do you need a Blockchain? ACR Cryptology ePrint Archive.

Yıldırım, F. (2015). Kripto paralar, blok zinciri teknolojisi ve uluslararasi ilişkilere muhtemel etkileri. Medeniyet Araştırmaları Dergisi, 2 (4), 81-97.

Yıldırım, H. (2018). Açık ve uzaktan öğrenmede Blok zincir teknolojisinin kullanımı. Açıöğretim Uygulamaları ve Araştırmaları Dergisi, 4(3), 142-153.

Yıldız, R. Ö., ve Baştuğ, S. (2018). Blok zincir teknolojisi kapsamında elektronik konşimento. 14.03.2019 tarinde www.researchgate.net Adresinden erişildi.

Yıldız, A. (2018). Endüstri 4.0 İle bütünleştirilmiş dijital tedarik zinciri. Business \& Management Studies: An International Journal, 6(4), 12151230.

Zhang, Y., ve Wen, J. (2015). An IoT electric business model based on the protocol of Bitcoin. In Proceedings (184-191) . 18th International Conference on Intelligence in Next Generation Networks, 17-19 February, Paris, France.

Ziegeldorf, J. H., Grossman, F., Henze, M., Inden, N., ve Wehrle, K. (2015). CoinParty: Secure multi-party mixing of Bitcoins. In CODASPY '15: Proceedings (75-86) 5th ACM Conference on Data and Application Security and Privacy, March 02 - 04, NY, USA. 
Zu, X., ve Kaynak, H. (2012). An agency theory perspective on supply chain quality management, International Journal of Operations $\mathcal{E}$ Production Management, 32(4), 423-446.

Zyskind, G., Nathan, O., Pentland, A. (2015). Decentralizing privacy: Using blockchain to protect personal data. IEEE CS Security Workshops, 180-184. 21-22 May, San Jose, CA, USA

\section{Kaynakça Bilgisi / Citation Information}

Bakan, İ. ve Şekkeli, Z.H. (2019). Blok zincir teknolojisi ve tedarik zinciri yönetimindeki uygulamaları. OPUS-Uluslararası Toplum Araştırmaları Dergisi, 11(18), 2847-2877. DOI: 10.26466/opus.563240 